\title{
A REINCIDÊNCIA CRIMINAL NO SISTEMA PENITENCIÁRIO BRASILEIRO
}

\author{
CRIMINAL REINCIDENCE IN THE BRAZILIAN PENITENTIARY SYSTEM \\ Carlos Eduardo Silva Abbadie ${ }^{1}$ \\ Tiago dos Santos Arão ${ }^{2}$ \\ Leonardo Mattos $^{3}$
}

RESUMO: O sistema carcerário brasileiro tem como um de seus escopos a reeducação de apenados, porém funciona de forma precária e ineficiente, sendo que o vasto número de reincidentes demonstra essa ineficiência por parte do Estado no seu processo ressocializador. Nesse contexto, a presente pesquisa será feita a partir da análise doutrinária no que tange ao tratamento da reincidência pelo sistema penitenciário brasileiro e a função preventiva específica das penas. Para tanto, verifica-se certos fatores que contribuem para a não reincidência no crime, buscando soluções técnicas para o problema e indicando falhas na execução das leis penais. Assim, o estudo tem como relevância ampliar as possibilidades do sistema na colaboração efetiva com o apenado, buscando orientar socialmente este egresso no sentido de minimizar a possibilidade de retorno ao sistema.

Palavras-chave: Sistema prisional. Reincidência criminal. Ressocialização. Lei de execuções penais.

ABSTRACT: Brazilian prison system has the reeducation of inmates as one of its scopes, although it works poorly and inefficiently as the vast number of recidivists demonstrates this inefficiency by the State in its resocializing process. In this context, this research will be held from the doctrinal analysis on the treatment of recidivism by the Brazilian penal system and the specific preventive function of executions. To this end, certain factors that contribute to the non-recidivism in crime are verified, seeking technical solutions to the problem and pointing out flaws in the enforcement of criminal laws. Thus, the study's relevance is to expand the possibilities of the system in effective collaboration with the convict, socially guiding this egress to minimize the possibility of returning to the system.

Keywords: Prison system. Criminal recidivism. Resocialization. Law of criminal executions

\footnotetext{
${ }^{\mathrm{I}}$ Especialista em ciências criminais Universidade Luterana do Brasil, ULBRA. Policial penal.

2 Especialista em segurança pública, UFPEL. Policial penal.

${ }^{3}$ MBA em Gestão Pública, faculdade Cidade Verde. Policial penal
} 


\section{INTRODUÇÃO}

A decadência do sistema penitenciário não remete somente à falta de políticas públicas, e sim à falta de estrutura e organização do complexo penitenciário, bem como a problemática da superlotação nas cadeias, tendo em vista a grande remessa de apenados, que só aumenta, e a contratação de pessoas não qualificadas para tratar diretamente com o reeducando.

Nessa esteira, o presente trabalho, inicialmente explanará um quadro atual sobre as penitenciárias brasileiras no que tange à reincidência, passando brevemente pelo Direito Penitenciário, pois para que se possa entender o sistema prisional brasileiro e a extrema necessidade de implementação de melhorias para a ressocialização dos apenados, é imperioso conhecer a realidade carcerária que nos cerca.

Em um segundo momento, objetiva-se esclarecer alguns pontos importantes da Lei de Execuções Penais, os quais não são aplicados e, se fossem, contribuiriam muito para o sistema carcerário atual.

Por fim, no terceiro capítulo, serão abordadas possibilidades que auxiliem no tratamento do apenado, ilustrando fatores que contribuem para a não reincidência no crime e elencando possibilidades para que o apenado, ao passar pelo sistema carcerário, não continue a atuar em atividade marginal.

Importante ressaltar, que o sistema penitenciário atual, juntamente com as leis que o embasam, tem o escopo de guardar, custodiar e ressocializar o apenado, para que este volte a conviver em sociedade e seja minimizada a reincidência penal. Justamente por isso, o presente estudo irá elencar essas possíveis tangentes que auxiliem no tratamento do apenado, contribuindo para que este não volte a delinquir.

Ademais, o elemento primordial do presente estudo é o indivíduo, mais especificamente o apenado, o qual é condenado a cumprir uma pena e, com isso, vivencia todos os problemas envoltos em um sistema prisional que padece de mazelas, cumprindo suas penas, muitas vezes, em condições sub-humanas e tendo seu desenvolvimento interrompido por diversas situações, que serão aqui expostas.

\section{Direito penitenciário brasileiro e a realidade das instituições de cumprimento de pena}

Para entender de forma adequada o presente estudo e adentrar com maior profundidade no foco principal do trabalho, primeiramente, é imperioso conhecer o direito penitenciário e a realidade das penitenciárias brasileiras, no que diz respeito à reincidência criminal.

Para isso, importante ressaltar, que a criminalidade sempre esteve presente na sociedade. Da mesma forma, desde sempre, procura-se um modo para que o criminoso pague pela ação delinquente, trazendo uma sensação satisfatória de segurança ao cidadão, e ainda uma forma de o Estado organizado mostrar sua força. Entende Fragoso como uma sanção retributiva, veja-se: 
Trata-se da sanção característica do direito penal, em sua essência retributiva. A sanção penal é em essência retributiva porque opera causando um mal ao transgressor. [...] Diz-se retributiva a sanção penal porque consiste num mal imposto ao transgressor em virtude da violação da norma jurídica. Esse mal é a perda de bens jurídicos: a vida (no caso da pena de morte), a liberdade (se a pena é de prisão) ou o patrimônio (no caso de pena de multa). (FRAGOSO, 1994, p. 279).

A primeira tentativa de construir um Código que estabelecesse normas com relação ao Direito Penitenciário Brasileiro veio por meio do projeto do Código Penitenciário da República, de 1933, elaborado por Cândido Mendes, Lemos de Brito e Heitor Carrilho. O projeto não chegou nem a ser discutido em virtude da instalação do regime do Estado Novo, o qual acabou por suprimir as atividades parlamentares.

Em 1957 foi sancionada a Lei $n^{\circ} \mathbf{3} .274$ que dispunha sobre normas gerais de regime penitenciário. Ocorre que, tal diploma tornou-se letra morta da lei. Depois disso, surgiram outros projetos, os quais não lograram êxito. Os anos foram: 1957, 1963 e 1970. Essa não conversão em lei fez com que a República continuasse carecendo de uma legislação que tratasse de forma mais específica do tema execução penal.

Por outro lado, conforme Nunes:

[...] o direito executivo penal cada vez mais se consolidava como sendo uma ciência autônoma, distinta do direito penal e do direito processual penal, e também jurídica, não apenas de caráter meramente administrativo. (NUNES, 2009, online).

Enfim, no ano de 1983, sem qualquer alteração de vulto, foi aprovada a Lei de Execução Penal, que levou o no 7.210 , promulgada em in de julho de 1984 e em vigor a partir de 13 de janeiro de 1985.

Segundo a mesma autora referida acima,

A lei de execução penal brasileira é tida como sendo de vanguarda, e seu espírito filosófico se baseia na efetivação da execução penal como sendo forma de preservação dos bens jurídicos e de reincorporação do homem que praticou um delito à comunidade. A execução penal é definitivamente erigida à categoria de ciência jurídica e o princípio da legalidade domina o espírito do projeto como forma de impedir que o excesso ou o desvio da execução penal venha a comprometer a dignidade ou a humanidade na aplicação da pena. (NUNES, 2009, online).

De fato, a aludida lei é moderna e trás em seu bojo a filosofia ressocializadora da pena privativa de liberdade, como forma de substituição às penas cruéis e desumanas, que em seu caráter mais brando em relação ao passado, ainda não trouxe uma solução total no que diz respeito à prevenção e repreensão da prática criminosa, principalmente pelo fato de a referida lei não ser seguida na prática. Para esclarecer melhor essa ideia, aduz Nery:

As ideias de "Estado" e de "Direito Penal" surgem a partir da necessidade de que os conflitos entre os seres humanos pudessem ser regrados e tratados impessoalmente em uma esfera pública. Assim, a modernidade se forma também 
ao se estabelecer uma sanção para aqueles que violam o pacto social e transgridem as normas legais. $O$ fato de alguém transgredir as normas praticando um ilícito penal, por exemplo, não autoriza a vingança. O Estado então, é chamado para dirimir o conflito. Após o julgamento através dos meios legítimos e legais, e, chegando-se a conclusão de que certa conduta é ilícita, portanto, contra as regras estabelecidas pela sociedade, é chegada a hora de pagar pelo mal que se fez. (NERY, 2005, online).

Também é importante levar em consideração que embora a privação de liberdade não tenha alcançado seus objetivos, como ressocializar o preso ou mesmo prevenir que a prática delituosa viesse a reincidir, é comprovado que foi um importante avanço em relação às penas aplicadas no passado.

Nesse norte, considerando que não é uma prática totalmente ideal, deveria pelo menos proporcionar o menor mal possível ao apenado, de modo que o modelo atual de encarceramento está longe de atingir o modelo que um Estado Democrático de Direito necessita e almeja. Assim também entende Oliveira:

\begin{abstract}
A falência do sistema penitenciário brasileiro é resultado do colapso dos diversos aspectos que o compõe, uma vez que as condições de sobrevivência no cárcere são totalmente degradantes, atentando contra o basilar princípio constitucional da dignidade da pessoa humana. Nesse sentido, o sistema prisional ao longo dos tempos tem se demonstrado incapaz de cumprir as medidas básicas de reabilitação do apenado, ou seja, o crime cresce de maneira descontrolada e a ressocialização do preso é o que menos ocorre, visto que os índices de reincidência carcerária só têm aumentado. Percebe-se, com isso, o imenso contraditório existente entre o que é previsto no texto constitucional e a realidade cruel e desumana do cumprimento das penas nas prisões brasileiras, pois o indivíduo é tratado de forma degradante. Dessa maneira, o processo falimentar do sistema penitenciário no país é creditado à dimensão da população carcerária, e à falta de investimento nas casas prisionais, ora por falta de recursos do ente estatal e também por total falta de interesse deste em investir na melhoria da qualidade de vida dos apenados. (OLIVEIRA, 2014, online).
\end{abstract}

Com relação a pena privativa de liberdade, isto é, a privação do direito de ir e vir, ressalta-se que o precário sistema carcerário nacional não diz respeito apenas ao falho sistema político penal para reeducar, como também a desestruturação do complexo carcerário, bem como falta de gestão e superlotação nos presídios, provocando, num contexto mais amplo, a reincidência. Assim compreende Menezes:

Nesse contexto, há ainda a percepção de que o sistema carcerário comete falhas nesse importante papel, visto que o grande número de presos que voltam a cometer crimes, após o término de suas penas, tornando-se reincidentes só cresce. O fato do apenado não estar preparado para o retorno ao convívio social após o término do cumprimento de pena, é um fator que faz aumentar a sua conduta ilícita. (MENEZES, 2014, online).

Realmente é difícil entender o retorno de pessoas egressas do sistema prisional. $O$ sistema está falido e as condições dentro de uma cadeia são desumanas: violência sexual, doenças, maior parte do dia condicionado em celas superlotadas. Em verdade, tudo isso 
gera consequências drásticas, que não cumprem, nem de longe, com o objetivo de ressocialização. Dessa forma também depreende Mirabete:

A ressocialização não pode ser conseguida numa instituição como a prisão. [...] A pena privativa de liberdade não ressocializa, ao contrário, estigmatiza o recluso, impedindo sua plena reincorporação ao meio social. A prisão não cumpre a sua função ressocializadora. Serve como instrumento para a manutenção da estrutura social de dominação (MIRABETE, 2002, p. 24).

No mesmo sentido Kuehne:

O que se constata no dia a dia, representado por números dramáticos, por situações que fazem eclodir as rebeliões nos cárceres e nos presídios, são as disputas de vagas, o sorteio - como há algum tempo ocorria em Minas Gerais em que o pacto de morte é selado entre os reclusos para permitir que ao menos possam deitar o corpo no chão, disputando aqueles míseros centímetros quadrados e não os metros quadrados assegurados pelo nosso ordenamento jurídico. (KUEHNE, 20or, p. I6).

Assim, em se tratando da complexidade do sistema carcerário, outro ponto a ser apontado é a qualificação dos profissionais que atuam nas penitenciárias, muitas vezes despreparados e desanimados com baixos salários. Menezes compreende nesse sentido:

Não há investimento em material humano qualificado nesse complexo sistema, que vai além de muros, abrangendo desde a figura do diretor, que esta ali para administrar a unidade prisional, implementando políticas e diretrizes referentes a execução de pena, como também, os técnicos, sendo importantes para elaboração de pareceres diários no que tange a saúde, na solução de problemas pessoais, realizando uma ligação entre o apenado dentro do presídio e fora dele. Os servidores em geral, médicos, dentistas, terapeutas, advogados sejam eles defensores públicos ou particulares, acompanhando e defendendo o apenado em seu processo disciplinar interno, os agentes penitenciários, mantendo a segurança e auxiliando no tratamento dos reeducandos. (MENEZES, 2014, online).

A bem da verdade, as penitenciárias que deveriam ter o objetivo de ressocializar estão sendo transformadas em faculdades do crime, possuindo um caráter corruptivo em relação aos servidores. Os apenados por vezes tem o comando de alguns presídios, e requerem direitos e regalias, com o famoso Direito de Proteção Humana, possuindo o sentimento de que podem tudo. É um disparato contra a sociedade e o Estado, e se a política criminal e a atuação do Estado não forem reformuladas, em um futuro muito próximo, o país estará vivendo uma possível guerra civil. 


\section{Lei de execução penal}

A Lei de Execução Penal, considerada um dos pilares do Direito Penal, destaca em seu artigo Io: "A execução penal tem por objetivo efetivar as disposições de sentença ou decisão criminal e proporcionar condições para a harmônica integração social do condenado e do internado" (Lei no $7.210 / 84$ ).

Em relação à execução das medidas de segurança, o Estado tem por objetivo prevenir o surgimento de novos crimes internando o inimputável ou semi-imputável, que apresenta periculosidade. Autores coadunam nesse sentido:

Percebe-se a dupla finalidade da execução penal qual seja, dar sentido e efetivação do que foi decidido criminalmente além de dar ao apenado condições efetivas para que ele consiga aderir novamente ao seio social e assim não cair nas antigas malhas do crime. A reinserção social tem como objetivo a humanização da passagem do detento na instituição carcerária, procura dar uma orientação humanista colocando a pessoa que delinquiu como centro da reflexão cientifica. (FIGUEIREDO NETO et al, 2orr, online).

Ainda, em seu artigo ıo a referida lei dispõe: "A assistência ao preso e ao internado é dever do Estado, objetivando prevenir o crime e orientar o retorno à convivência em sociedade" (Lei no $7.210 / 84$ ).

Em síntese, o Estado deveria aplicar o direito de punir, inibindo o criminoso em relação ao surgimento de novos delitos. Com a punição, apresentaria para a sociedade, que busca por justiça, uma resposta ao ato delitivo, tentando a readaptação do condenado socialmente e oferecendo-lhe atributos que o ajudem a tornar-se útil a si mesmo, à sua família e a sociedade.

Infelizmente, o que está disposto no referido texto legal está longe de ser efetivamente cumprido nos estabelecimentos prisionais brasileiros. Por mais que a Lei de Execução Penal possua em seu bojo inúmeros meios para que sejam atingidas as finalidades da pena, o Estado não proporciona estrutura alguma para o seu cumprimento.

Conforme entende Assis: "O Brasil convive com um abandono do sistema prisional, o que deveria ser um instrumento de ressocialização, muitas vezes, funciona como escola do crime, devido à forma como é tratado pelo Estado e pela sociedade" (ASSIS, 2007, online).

E, mais uma vez, destaca-se, que a Lei de Execução Penal realmente apresenta em seu texto os recursos necessários para alterar o panorama em que hoje se encontra o sistema prisional. Se fosse literalmente aplicada, alcançaria benefícios não só para os detentos, que estão confinados, mas para toda sociedade. Isto, pois, trás em seu texto, muitas garantias aos apenados, obedecendo aos princípios constitucionais, assegurados aos mesmos e, noutro giro, beneficiando a sociedade de uma forma geral. 
Ocorre que, essencial seria a participação não só dos que tratam diariamente com os apenados, como agentes, técnicos, diretores, como também da família e, principalmente, do Estado, que de uma vez por todas, precisa efetivar a sua responsabilidade e aplicar investimentos para um melhor e mais eficiente programa ressocializador.

Aduz Nery Junior e Nery (2006, p. 164) que "incumbe ao Estado adotar medidas preparatórias ao retorno do condenado ao convívio social”.

Ressalta-se também, que não é necessária a implementação de mais leis a respeito do assunto, pois iria congestionar e burocratizar ainda mais o judiciário. Dessa forma,

\footnotetext{
Não se pode deixar de lado o intuito real da Lei de Execução Penal que vai além da pena. A recuperação do indivíduo é objetivo marcante na LEP que trata diversas vezes sobre as maneiras dessa reintegração ser efetivada, seja através do trabalho, das muitas assistências de que ela trata e ainda através da eficiência dos órgãos que ela traz para ajudar nessa ressocialização. Retrata com clareza que se faz pertinente esse trabalho tendo como aliados normatização eficaz, e junção de forças entre os que estão trabalhando mais próximos aos apenados e sua família que os receberá quando de sua saída da penitenciária. (FIGUEIREDO NETO et al, 2orr, online).
}

Por fim, resta claro que o legislador, quando elaborou a Lei de Execução Penal, tinha por objeto principal respeitar o princípio da dignidade humana, assegurando ao reeducando saúde, educação, respeito, trabalho, remição, assistência, etc. A referida lei almeja que um cronograma seja executado desde a entrada do apenado ao sistema prisional até sua saída, devolvendo um indivíduo melhor para a sociedade.

Dessa forma, abaixo, tratar-se-á das possibilidades que podem auxiliar no tratamento dos apenados, elencando possibilidades para que o apenado não continue a atuar criminosamente.

\section{Alternativas no tratamento do apenado}

Não resta dúvidas que o elemento primordial deste trabalho é o indivíduo, mais especificamente o apenado, que é condenado a cumprir uma pena e vivenciar os problemas crônicos do cárcere, caracterizados basicamente por pessoas jovens, originariamente de classes humildes e pouco favorecidas, tendo o seu direito de ir e vir privado.

Por esses motivos, e mais alguns que a miséria e a prisão proporcionam, não tiveram o privilégio de acesso à educação e à formação profissional, e por isso, tornam-se indivíduos excluídos do mercado de trabalho, sofrendo com o estigma de serem exdetentos, o que os leva quase sempre a reincidir. Vejamos o que ensina Martins Filho:

O trabalho sem dúvidas é fator crucial para a mudança no individuo tanto dentro dos sistemas prisionais, como fora quando dificulta que o detento volte ao mundo do crime, reincidindo em práticas ilícitas. (MARTINS FILHO, 2014, online). 
Dessa forma, é imperioso salientar a importância do trabalho do apenado dentro e fora do cárcere, sendo este uma forma de combate à reincidência. A finalidade é que o indivíduo, encarcerado ou não, enxergue no labor uma forma de reinserção no convívio em sociedade. Assim entende Oliveira:

Convém ressaltar que o trabalho como um direito possibilita ao apenado incluí-lo
no sistema progressivo de cumprimento da pena. Já no que concerne ao trabalho
como dever, este se caracteriza como uma importante função que possibilita a
reinserção do indivíduo no contexto social, dando-se início ao processo
ressocializador. (OLIVEIRA, 2ol4, online).

Em outras palavras, é de fundamental importância que o Estado preencha o tempo ocioso que faz parte do dia a dia dos presídios brasileiros. Esse tempo improdutivo que o apenado fica na cela poderia ser utilizado de forma a oferecer a ele condições para o retorno à sociedade através da educação, trabalho e regras de convívio, evitando que a utilização desse "tempo" sirva para arquitetar novos crimes, alimentar sentimentos de raiva e de vingança para com a sociedade, aliar-se a elementos de alta periculosidade, planejar as rebeliões e fugas dos presídios, assim reincidindo na prática criminosa quando postos em liberdade.

O trabalho e a educação retiram os condenados do ócio, o qual é prejudicial a todo o sistema prisional e a sociedade. Assim leciona Lima:

Segundo Domenico de Masi, em sua obra “O ócio criativo”, ele aborda a essencialidade de educar através do tempo livre, isto é através de atividades lúdicas e culturais leva-se ao ócio inteligente, no qual se pode transformar esta ocasião em um momento de crescimento intelectual. Pode até parecer estranho esta analogia no que se refere à vida que se tem dentro dos presídios, mas se realmente fosse adotado a filosofia de ensinar um ofício a estes detentos de maneira que eles pudessem sentir prazer em ler e pensar, de onde poderiam até surgir ideias salutares a serem implantadas dentro da realidade prisional e assim se sentiriam mais úteis. (LIMA, 2oro, online).

Tanto o trabalho como a educação encontram-se inseridos dentro da Lei de Execução Penal no seu artigo 28. Veja-se: "O trabalho do condenado, como dever social e condição de dignidade humana, terá finalidade educativa e produtiva” (Lei no 7.210/84).

Importante ser levado em consideração as habilidades e condições pessoais de cada detento para produzir de acordo com sua capacidade física ou mental. É fato que ao oferecer uma formação profissional como direito do preso ou como dever do Estado, resta facilitado o futuro para o egresso, favorecendo sua reinserção social, e ainda prevenindo a reincidência.

Ocorre que, infelizmente, o Estado não possui condições eficazes de atuar para a recuperação dos apenados. Por isso, o artigo $4^{\circ}$ da Lei de Execução Penal aduz o seguinte: "O Estado deverá recorrer à cooperação da comunidade nas atividades de Execução da Pena e da medida de segurança" (Lei no $7.210 / 84$ ). 
Assim, se faz extremamente necessária a iniciativa privada e da população interessada em ajudar, fornecendo aos condenados demonstrações de empenho, através de novas oportunidades, desenvolvendo projetos que orientem na ressocialização do preso, dentro e fora das prisões, e mantendo vivo o Conselho da Comunidade, disposto no artigo 8o da Lei de Execução Penal.

Dessa forma, todos colaborarão para uma visão melhor da sociedade em relação ao egresso. Isto, pois, apenas dando ao apenado uma condição de um retorno favorável à sociedade é que se terá êxito verdadeiramente ressocializador, tendo uma aceitação sem preconceitos.

Mirabete (2004) nos fornece sua contribuição a respeito do assunto:

[...] a ausência prolongada do condenado de seu meio social acarreta um desajustamento que somente poderá ser superado se forem oferecidas a ele condições adequadas a sua reinserção social quando for liberado. É preciso pois, que toda a comunidade seja conscientizada da missão que lhe cabe na tarefa de assistir aquele que, tendo transgredido a lei penal, está resgatando o débito criado com a prática do crime. (MIRABETE, 2004, p. 246).

O Conselho da Comunidade trata-se, portanto, de um órgão da execução que colabora e fornece os meios necessários para os apenados alcançarem a completa reinserção social, visando neutralizar os efeitos danosos da marginalização.

Para tanto, existe desde 1972 um método conhecido como APAC (Associação de Proteção e Assistência aos Condenados), idealizado pelo Dr. Mário Ottoboni, advogado e membro da pastoral carcerária, com a finalidade precípua de desenvolver atividades para promover a recuperação dos condenados.

A APAC trabalha paralelamente ao Estado, na qualidade de Órgão Auxiliar da Justiça e da Segurança na Execução da Pena, conforme estabelecido em seu Estatuto Social. Nas palavras de seu fundador, a APAC devolve a sociedade apenas indivíduos em condições de respeitá-la, isto pois "não existem condenados irrecuperáveis, mas, tão somente, os que não recebem tratamento adequado" (OTTOBONI, 1997, p. 50).

A diferença entre o método APAC e o sistema carcerário comum é que, naquela, os presos são corresponsáveis pela recuperação uns dos outros, além de receberem assistência espiritual, médica, psicológica e jurídica fornecida pela comunidade.

Segundo Ottoboni (1997, p. 34) o método APAC tem uma tripla finalidade: é órgão auxiliar da justiça, protege a sociedade e é um órgão de proteção aos condenados.

Na visão do Superior Tribunal de Justiça (STJ):

A APAC considera os presos como reeducando, partindo do pressuposto de que todo ser humano é recuperável, desde que haja um tratamento adequado. Os 
princípios seguidos são os da individualização do tratamento; da redução da diferença entre a vida na prisão e a vida livre; da participação da família e da comunidade no processo de ressocialização; e do oferecimento de educação moral, assistência religiosa e formação profissional (SUPERIOR TRIBUNAL DE JUSTIÇA apud BUTELLI, 2orI, p. i8).

Importante ressaltar, que existem doze elementos fundamentais do método APAC, quais sejam: participação da comunidade; ajuda mútua entre os recuperandos; o trabalho; a religião; assistência jurídica; assistência à saúde; valorização humana; integração da família; trabalho voluntariado; centro de reintegração social (CRS); conquistas de benefícios por mérito; e a jornada de libertação em Cristo.

Além dos pontos abordados, outro assunto importante de trazer a baila é a necessidade de investimento nos servidores do sistema por meio de cursos de formação especializados, aperfeiçoamento, reciclagem, valorização salarial, cursos de dinâmica de trabalho em grupo, entre outros. O servidor tem que estar sempre atualizado, tendo como a capacidade de trabalhar em equipe a principal das qualificações. Assim também observa Ricci e Souza:

O sistema penal é muito complexo e vai muito além dos muros, pois, como se
pode observar, ele abrange estudos e observações de antes do cometimento do
crime, passando pelo cumprimento da pena e pelas consequências pós pena. Nesse
contexto, todo o trabalho a ser desenvolvido dentro do sistema prisional envolve
profissionais de vários ramos. Assim, várias atividades dentro de uma unidade
prisional são desenvolvidas de maneira interdisciplinar. Com isso, o
entrosamento desses profissionais é primordial para o bom andamento dos
trabalhos. Um profissional depende do trabalho do outro dentro do sistema
penitenciário. Resumidamente, pode-se dizer que os profissionais aqui envolvidos
possuem atribuições diferentes, mas o mesmo objetivo. (SOUZA; RICCI, 2or2,
online).

É preciso investir mais, muito mais, como já explanado acima, em material humano, técnicos que possam acompanhar o histórico do apenado, tentando diminuir a sua reincidência no crime, orientando em problemas pessoais, trabalho, educação, saúde, ligando o apenado com a realidade fora do presídio, uma realidade no que tange a sociedade. Melhor colocado nas palavras de Menezes:

Não há investimento em material humano qualificado nesse complexo sistema, que vai além de muros, abrangendo desde a figura do diretor, que esta ali para administrar a unidade prisional, implementando políticas e diretrizes referentes a execução de pena, como também, os técnicos, sendo importantes para elaboração de pareceres diários no que tange a saúde, na solução de problemas pessoais, realizando uma ligação entre o apenado dentro do presídio e fora dele. Os servidores em geral, médicos, dentistas, terapeutas, advogados sejam eles defensores públicos ou particulares, acompanhando e defendendo o apenado em seu processo disciplinar interno, os agentes penitenciários, mantendo a segurança e auxiliando no tratamento dos reeducandos. Ou seja, é imperioso o envolvimento de vários ramos dentro do sistema prisional, sendo primordial para o bom andamento dos trabalhos, sendo esses profissionais envolvidos por um mesmo objetivo a reabilitação, ou recuperação dos apenados. Assim sendo, é 
imperioso o investimento em capacitação, melhoria de condições de trabalho, em equipamentos e valorização de pessoal. O profissional do sistema prisional deve conhecer bem não só as suas atribuições mas as atribuições dos outros profissionais envolvidos no sistema, pois só assim ele poderá colaborar de maneira efetiva para ressocialização do apenado. (MENEZES, 2014, online).

Cabe salientar que todo esse investimento ainda não é definitivo no que refere a volta de ex detentos ao cárcere, pois o sistema atua quando o preso já possui uma personalidade formada, onde a família, a escola, a sociedade e o próprio Estado falharam. Veja-se:

Assim, o cumprimento de pena no Brasil deve ser visto e repensado, com olhos postos em novas formas de tratamento do apenado. Contudo, é apenas uma parte do problema ou a menor delas, pois o mesmo pensamento dispensado com o apenado deve prevalecer no que diz respeito as melhorias de condições de vida das classes mais abastadas, com uma melhor distribuição de renda, propiciando assim melhores condições de educação, saúde, segurança, lazer entre outros. (SOUZA; RICCI, 2012, online).

Atento para isso, também é importante observar a correta aplicação de dispositivos que venham a acrescentar na diminuição da reincidência criminal, como o ingresso no sistema e a consequente individualização de sua pena, buscando evitar influências negativas da prisão.

Com isso, é cristalino que o sistema carcerário no Brasil possui muitos problemas e sua estrutura necessita urgentemente de planejamento e organização, para tentar ao menos se aproximar da efetividade da Lei de Execução Penal.

\section{CONSIDERAÇÕES FINAIS}

O presente trabalho teve como escopo elucidar o sistema prisional Brasileiro e a Lei de Execução Penal, principalmente no que concerne a realidade do sistema e a previsão legal, demonstrando que, depois de aprovada uma lei tão moderna e teoricamente eficaz na busca pela ressocialização, ela não é aplicada pelo Estado, assim como o mesmo não efetiva sua responsabilidade, nem aplica investimentos para um melhor e mais eficiente sistema penitenciário.

Diante do que foi exposto resta claro entender, que o falho sistema político penal, a deficiência nos programas de reabilitação, as precárias condições prisionais, a falta de gestão dos estabelecimentos prisionais, a superlotação e a exposição às redes criminosas nos cárceres combinam-se e influem negativamente como aspectos reprodutores $\mathrm{da}$ violência e do crime, provocando, a reincidência.

Uma importante contribuição para solucionar o grave problema da reincidência, seria a qualificação dos profissionais que atuam nas penitenciárias, os quais poderiam acompanhar o histórico do apenado, orientando em problemas pessoais, trabalho, educação, saúde e ligando o apenado com a realidade fora do presídio. 
Ressalta-se, que reformar o sistema penitenciário não seria uma solução definitiva para eliminar a reincidência, pois o apenado já possui a sua personalidade formada, ou seja, necessita de um trabalho ressocializador, baseado na profissionalização, que molde, ao menos em parte, sua convivência na sociedade.

A Lei de Execução Penal tem muitos instrumentos para contribuir na problemática da reincidência, possuindo recursos necessários para alterar o panorama em que hoje se encontra o sistema prisional. Se fosse literalmente aplicada, alcançaria benefícios não só para os detentos, mas para a sociedade de uma forma geral.

Fatores como o cumprimento da Lei de Execução Penal, boa vontade da direção das casas prisionais, trabalho e educação profissionalizante, aliados à ajuda da sociedade, seriam fundamentais para ajudar no tratamento dos apenados.

A ajuda conjunta da iniciativa pública e privada em relação aos paradigmas existentes entre o estabelecimento penal e a vida em sociedade, direcionaria para uma mudança na visão da sociedade em relação ao egresso.

Destaca-se, também, que o trabalho e a educação são uma forma importante de combate à reincidência, pois retiram o apenado do ócio, possuindo uma finalidade educativa e produtiva.

Além disso, um importante e inovador método, chamado APAC, pode ajudar positivamente devolvendo ao convívio da sociedade indivíduos em condições de respeitála, conforme dito pelo idealizador do mesmo. Aliás, a diferença entre o método APAC e o sistema carcerário comum é que, naquela, os apenados são corresponsáveis pela recuperação uns dos outros e recebem todo tipo de ajuda fornecida pela comunidade.

Outro ponto relevante a ser concluído, é que os aspectos da própria sociedade também deveriam mudar, pois muitas vezes é ela que propicia o ambiente de vício e corrupção, a falta de trabalho, a defeituosíssima organização penal e penitenciária, criando as circunstâncias que arrastam à reincidência.

Contudo, não restam dúvidas que o sistema carcerário Brasileiro possui inúmeros problemas e sua estrutura falida necessita urgentemente de planejamento, organização e empenho, para efetivar tudo que está disposto na Lei de Execução Penal.

Mais especificamente, necessita-se de pessoas e instituições trabalhando na execução de projetos verdadeiramente ressocializadores, contribuindo não só para a reeducação do apenado, mas sim na segurança que a sociedade necessita em reaver esse reeducando no convívio social, fornecendo-lhe condições de um retorno favorável e ensejando uma reintegração sem preconceitos. 


\section{Referências bibliográficas}

ASSIS, Rafael Damaceno de; A realidade atual do sistema penitenciário Brasileiro. Disponível em: $<$ http://br.monografias.com/trabalhos9o8/a-realidade-atual/a-realidadeatual.shtml $>$. Acesso em: 21.fev.202I.

BRASIL. Lei de execução Penal. Lei no 7.210 de II de julho de 1984.

BUTELLI, Karyne Aranha Diniz; Projeto novos rumos na execução penal e o método APAC - uma abordagem jurídica e filosófica acerca da eficácia da lei 7210/84. Trabalho de Conclusão de Curso apresentado à Escola de Direito do Centro Universitário da Cidade UniverCidade. Rio de Janeiro, 2oII.

FIGUEIREDO NETO, Manoel Valente et al; A ressocialização do preso na realidade brasileira: perspectivas para as políticas públicas. Disponível em:

〈https://ambitojuridico.com.br/cadernos/direito-penal/a-ressocializacao-do-preso-narealidade-brasileira-perspectivas-para-as-politicas-publicas/>. Acesso em: 25.fev.202I.

FRAGOSO, Heleno Cláudio; Lições de Direito Penal: a nova parte geral. 4. ed. Rio de Janeiro: Forense, 1994.

KUEHNE, Maurício; Privatização dos Presídios. R. CEJ, Brasília, 2oor.

LIMA, Elke Castelo Branco; A ressocialização dos presos através da educação profissional. Disponível em: <http://www.direitonet.com.br/artigos/exibir/5822/A-ressocializacaodos-presos-atraves-da-educacao-profissional>. Acesso em: 02.mar.202I.

MARTINS FILHO, Klezer Catunda; Alternativas de reinserção dos ex-detentos no mercado de trabalho. Disponível em: $<$ http://www.webartigos.com/artigos/alternativasde-reinsercao-dos-ex-detentos-no-mercado-de-trabalho/r25584/>. Acesso em: 24.fev.2021.

MENEZES, Priscilla Pereira de; A reincidência em decorrência da precariedade do Sistema Carcerário. Disponível em: $\langle$ http://www.conteudojuridico.com.br/artigo,areincidencia-em-decorrencia-da-precariedade-do-sistema-carcerario,50763.html >. Acesso em: 25.fev.2021.

MIRABETE, Julio Fabbrini; Execução Penal. Comentários à Lei 7.210, de II-7-1984. II São Paulo: Atlas, 2004.

MIRABETE, Julio Fabbrini; Execução Penal. io ed. São Paulo: Atlas, 2002.

NERY, Bruna Barreto; O Cárcere e seus problemas. Disponível em:

〈http://www.direitonet.com.br/artigos/exibir/2107/O-carcere-e-seus-problemas >. Acesso em: 27.fev.2021. 
NERY JUNIOR, Nelson; NERY, Rosa Maria de Andrade; Constituição Federal Comentada e Legislação Constitucional. São Paulo, 2006.

NUNES, Amanda Poliana Ferreira; (In)eficácia das penas: o aumento da reincidência criminal. Disponível em: <https://conteudojuridico.com.br/openpdf/cjo41792.pdf/consult/cjo4I792.pdf>. Acesso em: 02.mar.2021.

OLIVEIRA, Maria Julia Bittencourt de; A Ressocialização do apenado através do trabalho, em face do principio da dignidade da pessoa humana. Disponível em: https://ambitojuridico.com.br/cadernos/direito-penal/a-ressocializacao-do-apenado-atraves-do-trabalhoem-face-do-principio-da-dignidade-da-pessoa-humana/>. Acesso em: 24.fev.202I.

OTTOBONI, Mário; Ninguém é irrecuperável: APAC - a revolução do sistema penitenciário. São Paulo: Cidade Nova, 1997.

SOUZA, Marcos Tudisco de; RICCI, Camila Milazotto; Sistema penitenciário e reincidência criminal. Disponível em: $<$ http://jus.com.br/artigos/22445/sistemapenitenciario-e-reincidencia-criminal>. Acesso em: 03.mar.2021. 